Tropical Journal of Pharmaceutical Research September 2015; 14 (9): 1597-1604

ISSN: 1596-5996 (print); 1596-9827 (electronic)

(C) Pharmacotherapy Group, Faculty of Pharmacy, University of Benin, Benin City, 300001 Nigeria.

All rights reserved.

Available online at http://www.tjpr.org

Original Research Article

http://dx.doi.org/10.4314/tjpr.v14i9.8

\title{
Phenotypic and Molecular Characterization of Plasmid- Encoded Extended Spectrum Beta-Lactamases Produced by Escherichia coli and Klebsiella spp from Lahore, Pakistan
}

\author{
Saba Riaz ${ }^{1,2 \star}$, Muhammad Faisal Bashir ${ }^{2}$ \\ ${ }^{1}$ Department of Microbiology and Molecular Genetics, University of the Punjab, Lahore 54590, ${ }^{2}$ Division of Microbiology, Citi
} Lab and Research Centre, 525 A Faisal Town, Lahore, Pakistan

*For correspondence: Email: saba.mmg@pu.edu.pk; Tel: 00923214530648

Received: 14 May 2015

Revised accepted: 8 August 2015

\begin{abstract}
Purpose: To investigate the distribution of plasmid-encoded extended spectrum beta-lacatamases (ESBLs) in Lahore, Pakistan using different phenotypic and molecular methods.

Methods: Escherichia coli and Klebsiella spp were obtained over a period of nineteen months (June 2007 to December 2008). Both were tested by the double disk synergy test, combined disk test and Epsiometer-test (E-test) to evaluate their ability to detect ESBLs. The genotypes of ESBLs were analyzed by monoplex polymerase chain reaction (PCR), multiplex PCR, DNA sequencing and isoelectric focusing.

Results: 662 E. coli and 153 Klebsiella spp were analyzed. Among these isolates, $39.3 \%$ E. coli and $26.1 \%$ Klebsiella spp were positive for extended spectrum beta-lactamases (ESBLs). $71.9 \%$ E. coli and $79.6 \%$ Klebsiella spp showed minimum inhibitory concentration (MIC) in the range $>32 / 0.064=500$ $\mu \mathrm{l} / \mathrm{mL}$ for cetatzidime/cetatzidime + clavulanic acid, while $66.5 \%$ E. coli and $69.1 \%$ Klebsiella spp revealed MIC in the range of $>16 / 0.016=1000 \mu \mathrm{l} / \mathrm{mL}$ for cefotaxime/cefotaxime + clavulanic acid. Antibiotic susceptibility testing revealed that imipemem, meropenem and tazocine were the most effective in the management of such infections. The most frequent genotype of ESBL was OXA (19.2 $\%)$ for E. coli and SHV (92.5\%) for Klebsiella spp. The highest genotypic combination found was the combination of TEM/OXA (44.2\%) for E. coli.

Conclusion: The resistance of E. coli and Klebsiella spp-producing ESBLs in Pakistan is a serious issue, and TEM, OXA and SHV type ESBL were the most common genotypes. Some isolates produced two or three genotypes at a time. Multiplex PCR of ESBL may help in early detection as well as phenotypic antibiotic therapy of these infections.
\end{abstract}

Keywords: Beta-lactamases, Escherichia coli, Klebsiella spp, Antibiotic susceptibility, Plasmidencoded, Structural genes, Imipemem, Meropenem, Tazocine

Tropical Journal of Pharmaceutical Research is indexed by Science Citation Index (SciSearch), Scopus, International Pharmaceutical Abstract, Chemical Abstracts, Embase, Index Copernicus, EBSCO, African Index Medicus, JournalSeek, Journal Citation Reports/Science Edition, Directory of Open Access Journals (DOAJ), African Journal Online, Bioline International, Open-J-Gate and Pharmacy Abstracts

\section{INTRODUCTION}

Antimicrobial resistance is a very serious issue all over the world. Pathogenic and opportunistic bacteria, which become highly resistant to drugs are causing untreatable infections [1]. Such bacteria are frequently reported as multidrug resistant bacteria (MDR) and some of the MDRs produce ESBL. The incidence and type of ESBL producer strains varies according to different geographical locations $[2,3]$. 
Plasmid-mediated extended-spectrum betalactamase (ESBL) confers resistance to cephalosporin group, such as ceftazidime, ceftriaxone and others. These enzymes occur in genera of the family Enterobacteriaceae for example Citrobacter, Enterobacter but predominantly present in E. coli and Klebsiella species [4]. The successful spread of ESBLs can be attributed to the fact that genes encoding for ESBLs are often located on self-transmissible or mobilizable broad range plasmids [5]. Change in the type of ESBL gene determines the activity of enzyme, for example if organisms producing TEM and SHV type ESBLs, apparent in vitro sensitivity to cefepime and to tazobactum is changed [6]. These drugs show an inoculum effect, with diminished susceptibility as the size of the inoculum was increased from $10^{5}$ to $10^{7}$ organisms. Strains having CTX-M-type and OXA-type ESBL are resistant to cefepime despite the use of standard inoculums [7].

Beta-lactams are important antibiotics in this part of world. Only few studies analyzing the extent of beta-lactam resistance based on their phenotypic features have been conducted. Very little is known about the molecular genotyping of extended spectrum beta-lactamases. The main objective of this work, therefore, was to determine beta-lactam resistant phenotypes and genotypes of $E$. coli and $K$. pneumoniae isolates from Lahore, Pakistan.

\section{EXPERIMENTAL}

\section{Bacterial isolation and identification}

A total of 1018 consecutive and non-duplicate lactose fermenting Enterobacteriaceae members were collected from Citi lab and Research Center during June 2007 to December 2008. All clinical specimens were processed according to standard operating procedures [8]. Lactose fermenting Gram-negative bacteria were characterized by colony morphology and biochemical tests. Confirmation of identification was performed by using API 20E (BioMerieux). Data were reported according to guidelines of Heath protection agency [9].

\section{Phenotypic detections tests}

Phenotypic test includes, double disk synergism augmentin (amoxicillin-clavulanate) was used to read the synergism with ceftriaxone $(30 \mu \mathrm{g})$, ceftazidime $(30 \mu \mathrm{g})$, aztreonam $(30 \mu \mathrm{g})$, cefotaxime $(30 \mu \mathrm{g})$. Combination disc $(\mathrm{CD})$ test was performed using ceftazidime/ceftazidime+ clavulanic acid and cefotaxime/cefotaxime+ clavulanic acid. Combination disk test was considered positive when there was $5 \mathrm{~mm}$ increase in zone of inhibition as compared to non-combination disc. E-test was performed as final phenotypic confirmatory test. Detection of ESBL was determined based on ratio between MIC of ceftazidime and cefotaxime alone or in combination with clavulanic acid using E-test strips.

\section{Confirmation by using ribotyping}

Isolates were also confirmed using 16SrRNA sequences. The PCR products were subsequently sequenced by Macrogen Bioengineering Co., Ltd. The nucleotide sequences were analyzed using BLAST software, available from the National Center for Biotechnology Information (http://www.ncbi.nlm. nih.gov). Phylogenetic analysis was performed using software seaview. Confirmed isolates were stored in trypticase soy broth containing $20 \%$ glycerol at $-80^{\circ} \mathrm{C}$ until use.

\section{Antibiotics susceptibility testing}

The antibiotic susceptibility was determined by disk diffusion on Mueller-Hinton agar (Bio-Rad, Marnes-la-Coquette, France). Multiple antibiotic resistances (MAR) of ESBL producing isolates according to gender and age groups of patients were calculated. The panel used in this study consists of 21 antibiotics that belong to three major groups of antibiotics according to mechanism of action. Such as antibiotic disks containing amikacin $30 \mu \mathrm{g}$, ampicillin $10 \mu \mathrm{g}$, amoxicillin clavulanic acid $(20 \mu \mathrm{g} / 10 \mu \mathrm{g}) 30 \mu \mathrm{g}$, carbencilin $100 \mu \mathrm{g}$, cephredine $30 \mu \mathrm{g}$, cefaperazone $75 \mu \mathrm{g}$, ciprofloxacin $5 \mu \mathrm{g}$, gentamicin $10 \mu \mathrm{g}$, nitrofurontoin $300 \mu \mathrm{g}$, imepenem $10 \mu \mathrm{g}$, meropenem $10 \mu \mathrm{g}$, norfloxacin $10 \mu \mathrm{g}$, cotrimoxazole $25 \mu \mathrm{g}$, ceftizoxime $30 \mu \mathrm{g}$, cefotaxime $30 \mu \mathrm{g}$, cefoxitin $30 \mu \mathrm{g}$, cetazidime 30 $\mu \mathrm{g}$, ceftriaxone $30 \mu \mathrm{g}$, cefixime $5 \mu \mathrm{g}$, aztreonam $10 \mu \mathrm{g}$, and pipracilin-tazobactam 100/10 $\mu \mathrm{g}$ were tested.

\section{Genotyping using PCR and sequence data analysis}

Colony PCR was performed following Jemima [10]. To differentiate bla $a_{S H V}, b / a_{T E M}, b / a_{O X A}$, the published primers were used [11]. Initially, singleplex PCR was optimized and then multiplex PCR assay of three-primer set was optimized (OXA, TEM and SHV genes) and performed. ATCC 25922 E. coli (SHV-negative), ATCC 700603 K. pneumoniae (SHV-positive), ATCC 
35218 E. coli (TEM-positive) and a strain of $E$. coli (OXA-positive) were used as control strains for PCR. Multiplex PCR was developed using primer set (OXA, TEM and SHV) in single reaction with maximum $25 \mu \mathrm{L}$ volume of PCR mixture. The PCR products were purified using Qiagen kit Agarose Gel DNA Purification Kit Version 2.0. Subsequently, the amplicons were sequenced by Macrogen Bioengineering Co., Ltd. The nucleotide and deduced protein sequences were compared to those available in GenBank.

\section{Isolectric focusing (IEF)}

Beta-lactamase was isolated using Massidda protocol [12]. Isoelectric focusing was performed using 2D gel electrophoresis (BioRad) following manufacturer instructions. Spot editing, scanning, quantification and evaluation of isoelectric points (pl) was calculated by ImageMaster 2D Elite v3.1 software (Amersham Biosciences).

\section{RESULTS}

\section{Bacterial isolates}

Out of 1018 Enterobacteriaceae members, 662 E. coli, 153 Klebsiella spp, 122 Enterobacter and 81 Citrobacter were isolated. Clinical samples positive for ESBL were as: urine (53\%), blood $(7.3 \%)$, wound swabs $(20.6 \%)$, foley catheter tip (10.3\%) and others (8.6\%). Total 300 bacterial strains were positive for beta-lactamases, $39.2 \%$ E. coli and $26.10 \%$ Klebsiella species were found to express ESBLs. Regarding gender classification in the case of beta-lactamase producing E. coli, females (60\%) had a higher incidence as compared to males (40\%). Similarly, in case of Klebsiella, more females (55 $\%$ ) than males (45\%) were affected. Comparison of hospitalized and community acquired infections revealed that in both cases $>55 \% E$. coli caused infection following Klebsiella > $45 \%$. Here data of E. coli and Klebsiella was arranged according to source of specimens. However, in the case of pus swabs, males were more infected by Klebsiella (71\%) than E. coli (69\%). In blood samples, E. coli showed higher infection rates (60\%) as compared to Klebsiella (40\%) for male patients. Frequency of infection of $E$. coli from Foley tip was less in males (29\%) than females $(71 \%)$. In Klebsiella, foley tip infections revealed more for females (62\%) than males (38 $\%)$. Other specimens had also high infection rate in females as compared to males.

\section{Phenotypic characteristics}

The isolates were further selected based on phenotypic detection test from hospitalized and community patients following Clinical and Laboratory Standard Institute (CLSI) guidelines [8]. Ceftazidime had high rate of synergism $(93.4,95 \%)$ followed by cefotaxime $(88.9,88.7$ $\%)$ aztreonam (86.2, $83.5 \%)$ and ceftriaxone (84.5, 83.1 \%). In Klebsiella spp highest synergism was found with ceftazidime $(88.4,89.1$ $\%)$ followed by aztreonam (88.6, $86.2 \%)$, cefotaxime (86.7, 89.6\%) and ceftriaxone (84.7, $88.5 \%$ ). Cephalosporin antibiotic ceftazidime, cefotaxime alone and combination disc were selected for further confirmation. E. coli was 99.2 $\%$ resistant to ceftazidime but was found $98 \%$ sensitive, $1.34 \%$ resistant and $0.74 \%$ intermediate to ceftazidime+clavulanic acid (disc). E. coli was more resistant to cefotaxime $(99.5 \%)$ and less resistant to cefotaxime+ clavulanic acid (disc) (3.84\%).

Cefotaxime+clavulanic acid (disc) increased $E$. coli sensitivity to $96.12 \%$. Klebsiella spp was $99.5 \%$ and $99.4 \%$ resistance to ceftazidime and cefotaxime, respectively. Combination discs of ceftazidime+clavulanic acid and cefotaxime+clavulanic acid altered resistance against ESBL to 1.36 and $2.12 \%$, respectively. It was observed that $2.8 \%$ E. coli and $1.4 \%$ Klebsiella spp had non-determinable > 32/> 4 (ND), while a majority of ESBL E. coli $(71.9 \%)$ and Klebsiella (79.6\%) groups fell in the range of MIC > 32/0.064 = $500 \mu \mathrm{l} / \mathrm{mL}$ for ceftazidime/ ceftazidime+clavulanic. For cefotaxime/ cefotaxime+clavulanic (CT/CTL), maximum ESBL E.coli $(66.5 \%)$ and Klebsiella (69.1\%) isolates were in the MIC range of $>16 / 0.016=$ $1000 \mu \mathrm{l} / \mathrm{mL}$ (Table 1).

\section{Susceptibility of isolates}

This panel is designed according to the CLSI guidelines [8]. This antibiotic panel is generally used in our hospitals and diagnostics labs. Out of 260 E. coli isolates > $97 \%$ were resistant to ampicillin, carbencilin, cephredine, cefuroxime, ceftriaxone and ceftazidime. E. coli isolates were $>80 \%$ and > $60 \%$ resistant to cefoperazone and ceftizoxime respectively. $E$. coli isolates were $50 \%$ resistant to amoxycillin/clavulanic acid.

Out of 40 Klebsiella isolates, $100 \%$ were resistant to carbencilin, cephredine, cefuroxime and ceftriaxone. Klebsiella isolates > $90 \%$ 
Table 1: E-test with cetazidime/cetazidime+clavulanic acid (TZ/TZL) and cefotaxime/cefotaxime+clavulanic acid (CT/CTL) MIC ratio

\begin{tabular}{|c|c|c|c|c|c|c|}
\hline \multicolumn{7}{|c|}{ Cetazidime/ cetazidime+clavulanic acid (TZ/TZL) MIC $(\mu \mathrm{l} / \mathrm{ml})$} \\
\hline MIC Ratio & $\begin{array}{c}>32 />4 \\
\text { (ND) }\end{array}$ & $\begin{array}{c}>32 / 0.064=5 \\
00\end{array}$ & $\begin{array}{c}>32 / 0.125=2 \\
56\end{array}$ & $24 / 0.19=126$ & $\begin{array}{c}16 / 0.38=4 \\
2.1\end{array}$ & $4 / 0.25=16$ \\
\hline E. coli & 2.8 & 71.9 & 14.6 & 7.4 & 1.3 & 2.0 \\
\hline $\begin{array}{l}\text { Klebsiella } \\
\text { spp }\end{array}$ & 1.4 & 79.6 & 9.3 & 4.5 & 5.2 & 0.0 \\
\hline \multicolumn{7}{|c|}{ Cefotaxime/ Cefotaxime +clavulanic acid $(\mathrm{CT} / \mathrm{CTL}) \mathrm{MIC}(\mu \mathrm{l} / \mathrm{ml})$} \\
\hline MIC Ratio & $\begin{array}{c}>16 />1 \\
\text { (ND) }\end{array}$ & $\begin{array}{c}>16 / 0.016=1 \\
000\end{array}$ & $\begin{array}{c}12 / 0.023=52 \\
1\end{array}$ & $3 / 0.023=130$ & $\begin{array}{c}8 / 0.125=6 \\
4\end{array}$ & $\begin{array}{c}4 / 0.094=4 \\
2.5\end{array}$ \\
\hline E. coli & 5.1 & 66.5 & 17.6 & 4.5 & 2.8 & 3.5 \\
\hline $\begin{array}{l}\text { Klebsiella } \\
\text { spp }\end{array}$ & 1.5 & 69.1 & 14.8 & 8.1 & 5.3 & 1.2 \\
\hline
\end{tabular}

resistant to ceftizoxime whereas > $80 \%$ were resistant to cefoperazone. $>60 \%$ resistance and $20 \%$ intermediate sensitivity to amoxycillin/ clavulanic acid were seen in Klebsiella isolates. E. coli and Klebsiella isolates showed highest susceptibility to imepenem followed by meropenem and tazocine. There was very rare resistance found to meropenum and tazocine (< $2 \%$ ), but no resistance was found to imepenem in both types of isolates. Hence, the most effective antibiotics that can be used as a therapy of choice in both types of isolates were imepenem followed by meropenem and tazocine. Protein inhibiting drugs, gentamicin and amikacin were also used. Klebsiella isolates $>80 \%$ and $E$. coli isolates $>60 \%$ were resistant to gentamicin. On the other hand amikacin responded well and showed highest activity for E. coli and Klebsiella spp. In nucleic acid inhibiting drugs $E$. coli showed $>80 \%$ resistance to ciprofloxacin and trimethoprim/sulfamethoxazole, while > $90 \%$ resistance to nitrofurontoin and norfloxacin. Klebsiella isolates had $>70 \%$ resistance to ciprofloxacin but > $90 \%$ resistance to trimethoprim/sulfamethoxazole, nitrofurontoin, and norfloxacin.

\section{Phylogenetic data}

Phylogenetic relation was developed using neighbor joining method ( $\mathrm{NJ}$ method). The tree length (sum of branch lengths) was 0.01111 in the case of $E$. coli (Figure 1) and 0.02171 in Klebsiella spp (Figure 2); branch lengths are proportional to the number of substitutions per site. Comparison of two bacterial groups was done using Parsimony analysis bootstrap 100 replicates along with control strains. K-TJW and K-ANT used as control Klebsiella spp while K12 that is used as control E. coli. Sequences were submitted to GenBank nucleotide database under accession numbers GU594294GU594311.

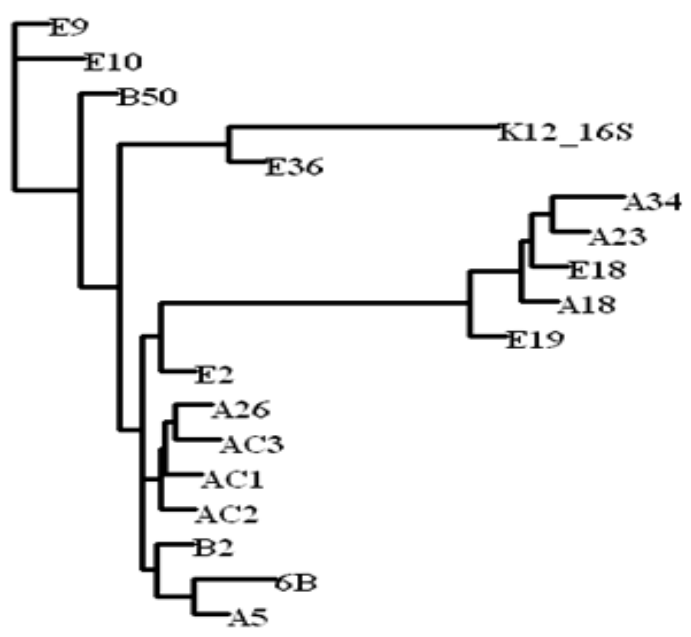

0.001

Figure 1: Phylogenetic tree from 14 aligned sequences of 1478 sites, based on the $\mathrm{NJ}$ method. The tree is rooted by outgroup B16

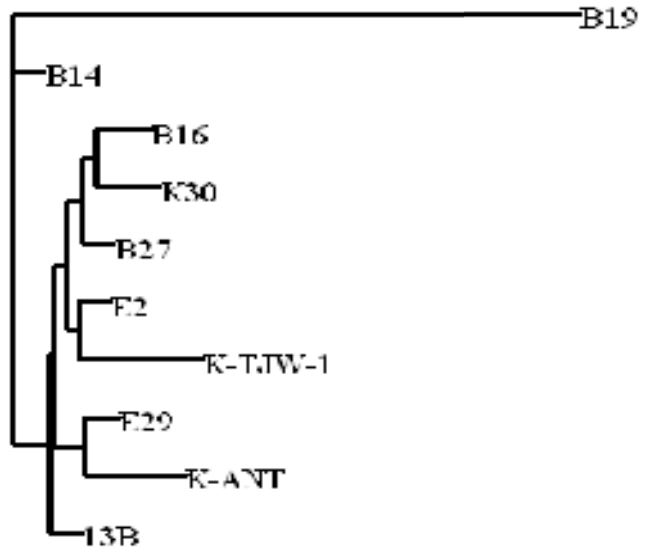

0101

Figure 2: Phylogenetic tree from 10 aligned Klebsiella sequences of 1608 sites, based on the NJ. The tree is rooted by outgroup B19 
Molecular phylogeny of the bla $a_{S H V}, b_{a_{T E M}}$ and $b^{b} a_{O X A}$ beta-lactamase genes

Distributions of TEM, OXA and SHV in bacterial isolates were observed (Table 2). Of the 260 clinical isolates of $E$. coli suspected to be ESBL producers $13.2 \%, \quad 19.2 \%$ and $7.6 \%$ demonstrated TEM, OXA or SHV-specific PCR products respectively. Combination of ESBL showed $44.2 \%, 3.8 \%, 1.5 \%, 1.9 \%$ of TEM/OXA, TEM/SHV, OXA/SHV, TEM/SHV/ $O X A$-specific products respectively. Sequence determination of PCR products obtained from $E$. coli and Klebsiella spp confirmed the identity of the genes (Figure 3). Of the 40 clinical isolates of Klebsiella spp $92.5 \%$ demonstrated SHVspecific products, $5 \%$ TEM/OXA and $2.5 \%$ TEM/SHV (Table 2). The nucleotide sequences reported in this paper have been submitted to the GenBank nucleotide database under accession numbers HM063036-HM063040 = SHV, $\mathrm{HM} 063041-\mathrm{HM} 063050=$ TEM, HM063051$\mathrm{HM} 063064=O X A$.

\section{IEF data}

Amino acids calculation showed that in SHV enzyme most frequent amino acid was Arginine

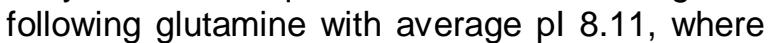
as in TEM beta-lactamase most frequent amino acid was Glutamine following Arginine with 4.47 pl. In OXA beta-lactamase most frequent amino acid was lysine, glutamine, aspartic acid following other amino acids. Average pl of OXA beta-lactamase calculated was 9.03 .

Table 2: Distribution of TEM, SHV and OXA in bacterial isolates $(\mathrm{n}=300$ : Note: Data in parenthesis indicate percent

\begin{tabular}{lccccccccr}
\hline $\begin{array}{l}\text { Bacterial } \\
\text { isolate }\end{array}$ & No & TEM & OXA & SHV & $\begin{array}{c}\text { TEM } / \\
\text { OXA }\end{array}$ & $\begin{array}{c}\text { TEM } \\
\text { ISHV }\end{array}$ & $\begin{array}{c}\text { SHVI } \\
\text { OXA }\end{array}$ & TEM/SHVIOXA & Others \\
\hline E. coli & 260 & $36(13.8)$ & $50(19.2)$ & $20(7.6)$ & $115(44.2)$ & $10(3.8)$ & $4(1.5)$ & $5(1.9)$ & $0(0)$ \\
$\begin{array}{l}\text { Klebsiella } \\
\text { spp }\end{array}$ & 40 & $0(0)$ & $0(0)$ & $37(92.5)$ & $2(5)$ & $1(2.5)$ & $0(0)$ & $0(0)$ & $0(0)$ \\
\hline
\end{tabular}

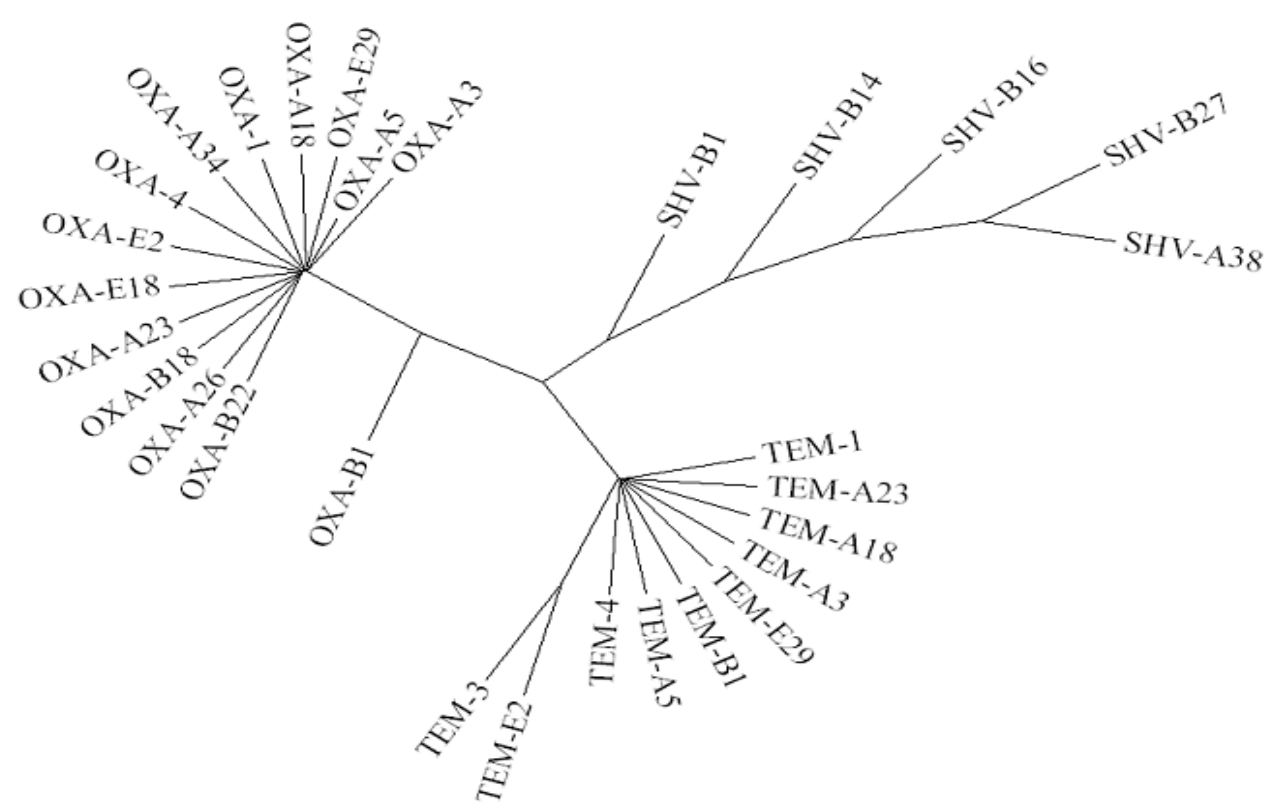

Figure 3: Parsimony analysis of OXA, TEM and SHV sequences. Analysis of OXA, TEM and SHV aligned sequences with bootstrap100 replicates, randomize sequence order 5

\section{DISCUSSION}

This research work was conducted because there was little available information regarding antimicrobial susceptibility and molecular characterization of ESBL genotypes of $E$. coli and Klebsiella spp in Pakistan. These members of Enterobacteriaceae are well known ESBLs producers and are responsible for nosocomial and community acquired infections [13]. Depending upon the rate of infecting isolates, $E$. coli and Klebsiella were considered as important research work. There are many reasons for the spread of infections, and these include misuse of 
antibiotics, animals and hospitals cross infection [4]. The prevalence of ESBLs can be different based on geographical areas. In Europe, ESBLs positivity was $1.3 \%$ of Escherichia coli and 18.4 $\%$ for Klebsiella pneumonia [14]. Several other reports are available for other areas like Latin America, Asia and also North America [15]. In 2003 about 30 \% ESBL producing E. coli were found in Aga Khan University research [12]. ESBLs producers were more commonly isolated from urinary tract infections (UTI) both in hospital and community-acquired infections [16]. In Iran, UTI causing ESBL producers were in high frequency [17]. Similarly in Japan the increased frequency of UTI caused by ESBL producers have been reported [18].

When data were analyzed according to gender and age groups it depicts that females were more infected. This complexity is because of lack of medical facilities in rural areas. High frequency of infected patients were observed either from young or old age group, this might be because of low immunity [13]. Data revealed that in Pakistan multidrug resistance was more common in the age group of $50+$ in both males and females [19]. Resistance appeared to be correlated with the old age as observed in another report [20]. In susceptibility profile imepemem, meropenem and tazocine were effective against ESBL isolates. Meropenem was considered as best option for therapy against gram-negative bacilli especially for cephalosporin resistant gram-negative bacilli [21]. The good activity of imepenem, meropenem and tazocin was also previously known [22]. Another work that supports this was conducted at King Fahd Hospital, Saudi Arabia. However, variability with other drugs such as amoxiclar augmentin, cefoperazone, ceftizoxime, gentamycin and ciprofloxacin was also observed [23].

Our data also suggest that majority of cases are positive for ESBLs as earlier reported [24]. Overall, phenotypic detection of clinical ESBL was $39 \%$ in E. coli and $26 \%$ in Klebsiella spp. In previous report, $53 \%$ K. pneumoniae and $44 \%$ E. coli were identified as suspected ESBL producer [25]. Comparative study of different phenotypic techniques revealed that double disc synergism (DDS) test was the most economical method of detection.

In current study multiplex PCR was developed for TEM, OXA and SHV genes. This method of diagnosing ESBL is a one-step procedure, which is very significant in diagnostics. There are a number of studies that showed the significance of using multiplex PCR in ESBL. Multiplex PCR for SHV and CTXM was developed in another study [26]. Multiplex PCR for detection of plasmid mediated quinolone resistance ESBL has also been developed [27]. The change in the antibiotic phenotype pattern in different ESBL, clearly differentiated the resistance mechanism of beta-alactamase producing isolates. This was solved by PCR, which accurately distinguished between different types of ESBL genes [28]. On sequence similarity analysis, it was found that tested isolates had 96 to $100 \%$ similarity to sequences of ESBL isolates from China. Klebsiella pneumoniae strain B27 (HM063040) SHV beta-lactamase producer had $98 \%$ similar sequence to clinical Klebsiella pneumoniae strain HS94 beta-lactamase [28]. Escherichia coli strain B1 (HM063048) TEM-beta-lactamase was $100 \%$ similar to Escherichia coli strain SA-Y1-39 [29].

\section{CONCLUSION}

ESBLs are an increasing problem in healthcare facilities, especially in rural areas. Imepemem, meropenem and tazocine remain good choices for treating infections. Addition of a combination disc in routine susceptibility testing gives satisfactory results for ESBLs in less time. TEM, $O X A$ and SHV type ESBLs were the most common genotype in this region.

\section{ACKNOWLEDGEMENT}

This study was supported a Research Project (2007-2010) funded by University of the Punjab. Part of this work was presented at International Congress on Infectious Diseases, Bangkok, Thailand. June 13 - 16, 2012.

\section{REFERENCES}

1. Wiegand I, Geiss HK, Mack D, Stürenburg E, Seifert $H$. Detection of Extended-Spectrum Beta-Lactamases among Enterobacteriaceae by Use of Semiautomated Microbiology Systems and Manual Detection Procedures. J Clin Microb 2007; 45: 11671174.

2. Behrooozi A, Rahbar M, Yousefi JV. Frequency of extended spectrum betalactamase (ESBLs) producing Escherichia coli and Klebseilla pneumonia isolated from urine in an Iranian 1000-bed tertiary care hospital. Afric J Microb Res 2010; 4: 81-84.

3. Xie L, Xu M, Yang T, Zhu C, Zhu B, Hu Y. Studies on Amino Acid Replacement and Inhibitory Activity of a $\beta$-Lactamase Inhibitory Peptide. Biochem 2010; 75: 336-341.

4. Vercauteren $P$, Descheemaeker $M$, leven $C$, Sanders $C$, Goossens $H$. Comparison of screening methods for the detection of extended-spectrum $\beta$ - lactamases 
and their prevalence among blood isolates of Escherichia coli and Klebsiella spin in a Belgian teaching hospital. J Clin Microb 1997; 35: $2191-$ 2197.

5. Szabó D, Melan MA, Hujer AM, Bonomo RA, Hujer KM, Bethel CR, Kristóf K, Paterson DL. Molecular Analysis of the Simultaneous Production of Two SHV-Type Extended-Spectrum Beta-Lactamases in a Clinical Isolate of Enterobacter cloacae by Using Single-Nucleotide Polymorphism Genotyping. AntiAge Chemo 2005; 49: 4716-4720.

6. Umadevi $S$, Kandhakumari G, Joseph NM, Kumar $S$, Easow JM, Stephen S. Prevalence and Antimicrobial Susceptibility Pattern of ESBL Producing Gram Negative Bacilli. J Clin Dia Res 2011; 5: 236-239.

7. Sattar A, Faqir $F$, Abbasi SA, Fraz A, Hussain $Z$. Changing Trends in Frequency of Extended Spectrum Beta Lactamase Producing Gram Negative Bacilli in Intensive Care Units of a Tertiary Care Hospital. Pak Arm for Med 2009; 4: 28-32.

8. Clinical Laboratory Standard Institute (CLSI). Reference method for broth dilution antifungal susceptibility testing of yeasts; approved standard-third edition; CLSI document M27-A3. 2008; Clinical and Laboratory Standards Institute, Wayne.

9. Health Protection Agency (HPA). Laboratory detection and reporting of bacteria with extended spectrum $\beta$ lactamases. 2006; National Standard Method QSOP 51 Issue 2. http://www.hpa-standardmethods. org.uk/documents/qsop/pdf/qsop51.pdf (accessed 17.01.2008).

10. Jemima SA, Verghese S. Multiplex PCR for bla CTX-M \& bla $S H V$ in the extended spectrum beta-lactamase (ESBL) producing Gram-negative isolates. Ind J Med Res 2008; 128: 313-317.

11. Colom K, Perez J, Alonso R, Fernandez-Aranguiz A, Larino $E$, Cisterna $R$. Simple and reliable multiplex $P C R$ assay for detection of blaTEM, blaSHV and blaOXA-1 genes in Enterobacteriaceae. FEMS Microb Lett 2003; 223: 147-151.

12. Massidda O, Rossolini GM, Satta G. The Aeromonas hydrophila cphA gene: molecular heterogeneity among class $B$ metallo- $\beta$-lactamases. J Bact 1991; 173: 4611-4617.

13. Coque TM, Baquero F, Canton R. Increasing Prevalence of ESBL-producing Enterobacteriacease in Europe. Eurosurvs 2008; 13: 1-11.

14. Nijssen S, Florijn A, Bonten MJ, Schmitz FJ, Verhoef J, Fluit AC. Beta-lactam susceptibilities and prevalence of ESBL producing isolates among more than 5000 European Enterobacteriaceae isolates. Int $\mathrm{J}$ Antim Agen 2004; 24: 585-591.

15. Babypadmini S, Appalara B. Extended Spectrum BetaLactamases in Urinary Isolates of Escherichia coli and Klebsiella pneumoniae Prevalence and Susceptibility Pattern in a Tertiary Care Hospital. Ind J Med Microb 2004; 22: 172-174.
16. Lachmayr KL, Kerkhof L, Dirienzo JAG, Cavanaugh CM, Ford TE. Quantifying Nonspecific TEM b-Lactamase (blaTEM) Genes in a Wastewater Stream. App Env Microb 2009; 75: 203-2011.

17. Jabeen K, Zafar A, Hasan R. Comparison of Double Disc and Combined Disc Method for the detection of Extended Spectrum B-Lactamases in Enterobacteriaceae. J Pak Med Asso 2003; 53: 534537.

18. Muratani T, Matsumoto T. Urinary tract infection caused by fluoroquinoloneand cephem-resistant Enterobacteriaceae. Int J Antim Agen 2006; 28(Suppl 1): S10-S13.

19. Bashir MF, Qazi Jl, Ahmad N, Riaz S. Diversity of Urinary Tract, and Drug Resistant Isolates of Escherichia coli in different age and gender Groups of Pakistanis. Trop J Pharm Res 2008; 7: 1025-1031.

20. Lindbäck H, Lindbäck J, Sylvan S, Melhus A. Low frequency of antibiotic resistance among urine isolates of Escherichia coli in the community, despite a major hospital outbreak with Klebsiella pneumoniae producing CTX-M-15 in Uppsala County. Scand J Infec Dis 2010; 42: 243-248.

21. Goel N, Chaudhary U, Aggarwal R, Bala K. Antibiotic sensitivity pattern of gram negative bacilli isolated from the lower respiratory tract of ventilated patients in the intensive care unit. Ind J Crit Car Med 2009; 13: 148-151.

22. Joly-Guillou M, Kempf $M$, Cavallo J, Chomarat $M$, Dubreuil L, Maugein J, Muller-Seriey C, RousselDelvallez M. Comparitive in vitro activity of Meropenem, Imipenem and Piperacillin/tazobactam against 1071 clinical isolates using 2 different methods: a French multicentre study. BMC Infec Dis 2010; 10: 72-76.

23. Al-Zahrani AJ, Akhtar N. Susceptibility Patterns of Extended Spectrum B-Lactamase (ESBL)-producing Escherichia coli and Klebsiella pneumoniae isolated in a teaching hospital. Pak Med Res 2005; 44: 64-67.

24. Cormican MG, Marshall SA, Jones RN. Detection of extended spectrum beta-lactamases (ESBL) producing strains by the E-test ESBL screen. J Clin Microb 1996; 34: 1880-1884.

25. Rodriguez-Villalobos $H$, Malaviolle V, Frankard J, Mendoca $R$, Nonhoff $C$, Struelens $M$. In vitro Activity of Temocillin against Extended-Spectrum $\beta$ lactamase-Producing Escherichia coli. J Antimicrob Chem 2006; 57: 771-774.

26. Jitsurong S, Yodsawat $S$. Prevalence Of ExtendedSpectrum Beta-lactamases (ESBLS) Produced In Blood Isolates of Gram-Negative Bacteria In A Teaching Hospital In Southern Thailand. Sout Asi J Trop Med Pub Heal 2006. 37: 131-135.

27. Cattoir V, Poirel L, Rotimi V, Soussy C, Nordmann P. Multiplex PCR for detection of plasmid-mediated quinolone resistance qur genes in ESBL-producing Enterobacterial isolates. J Antim Chem 2007; 60: 394-397.

Trop J Pharm Res, September 2015; 14(9): 1603 
28. Kao C, Liu M, Lin C, Huang Y. Antimicrobial Susceptibility and Multiplex PCR Screening of AmpC Genes from Isolates of Enterobacter cloacae, Citrobacter freundii, and Serratia marcescens. J Microb Immun Infec 2010; 43: 180-187.
29. Wang C, Dang H, Ding Y. Incidence of diverse Integrons and beta-lactamase genes in environmental Enterobacteriaceae isolates from Jiaozhou Bay, China. Worl J Microb Biotech 2008; 24: 2889-2896. 